\title{
SAFETY OF DIAGNOSTIC EVALUATION UNDER ANAESTHESIA WITHOUT ENDOTRACHEAL INTUBATION FOR HEAD NECK SQUAMOUS CELL CARCINOMA PATIENTS- WHEN SHOULD WE AVOID
}

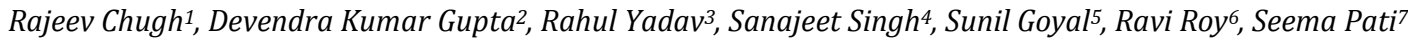 \\ ${ }^{1}$ Head and Neck Oncosurgeon, Department of ENT, Army Hospital $R \&$ R, Dhaula Kuan, New Delhi, India. \\ ${ }^{2}$ Head and Neck Oncosurgeon, Department of ENT, Army Hospital $R \& R$, Dhaula Kuan, New Delhi, India. \\ 3 Professor, Department of ENT, Army Hospital R \& R, Dhaula Kuan, New Delhi, India. \\ ${ }^{4} H O D$, Department of ENT, Army Hospital R \& R, Dhaula Kuan, New Delhi, India. \\ ${ }^{5}$ Classified Specialist ENT, Department of ENT, Army Hospital R \& R, Dhaula Kuan, New Delhi, India. \\ ${ }^{6}$ Classified Specialist ENT, Department of ENT, Army Hospital $R \&$ R, Dhaula Kuan, New Delhi, India. \\ ${ }^{7}$ Resident, Department of ENT, Army Hospital R \& R, Dhaula Kuan, New Delhi, India.
}

\begin{abstract}
BACKGROUND
ABSTRACT

Airway management is a very important aspect during head and neck squamous cancer (HNSCC) diagnostic procedures under anaesthesia, as the upper airway is shared by the anaesthesiologist as well as the surgeon. Adequate airway management is essential during these procedures due to safety issues and cost effectiveness and also to prevent an airway emergency. There is always a question of which patients need endotracheal intubation and in whom we should avoid. We wanted to assess the merits and demerits of upper airway diagnostic procedures in HNSCC under general anaesthesia with or without endotracheal intubation and determine the factors which may lead to an airway emergency or endotracheal intubation.
\end{abstract}

\section{METHODS}

This is a retrospective observational study of consecutive HNSCC patients, who underwent diagnostic or therapeutic rigid laryngoscopy under anaesthesia between Dec 2015 till Jul 2017 (retrospective) and Aug 2017 till December 2018 (prospectively maintained database) at a tertiary referral centre. Consecutive patients of HNSCC who underwent diagnostic endoscopy under anaesthesia for biopsy or mapping of the disease were included in the study. 393 patients' data was screened, out of which 303 patients were eligible for our study. 90 patients were excluded from the study, 30 were in stridor and 60 had a prior tracheostomy at the time of diagnostic evaluation. Various factors were evaluated for endotracheal intubation.

\section{RESULTS}

303 consecutive patients' database was analysed. Male:Female ratio was 93:210 (1:2.3); age ranged from 27 years to 81 years; mean age was 43 years; body mass index ranged from 17-33 with median 20. The site of lesion (glottis) and prior treatment were found to be significant factors for elective intubation. Micro-laryngoscopic procedure was found to be significant for endotracheal intubation. Rest all procedures can be safely performed with total intravenous anaesthesia (TIVA).

\section{CONCLUSIONS}

Direct laryngoscopy with or without biopsy for UADT SCC is safe without intubation baring few cases. We can do a DL Scopy next day of visit to our centre in per primum, thereby reducing the waiting period and establishing diagnosis early and hence reducing overall treatment time. it is cost effective. Patients with prior cancer directed treatment need intubation because of altered anatomy and neck tissue fibrosis. ML scopy takes longer time; hence, apnoea technique is not recommended due to $\mathrm{CO}_{2}$ retention; intermittent intubation through the laryngoscope is acceptable.

\section{KEY WORDS}

Head Neck Squamous Cell Cancer, Direct Laryngoscopy, Micro-Laryngoscopy, Total Intravenous Anaesthesia

HOW TO CITE THIS ARTICLE: Chugh R, Gupta DK, Yadav R, et al. Safety of diagnostic evaluation under anaesthesia without endotracheal intubation for head neck squamous cell carcinoma patients- when should we avoid. J. Evolution Med. Dent. Sci. 2019;8(30):2380-2384, DOI: 10.14260/jemds/2019/521

\section{BACKGROUND}

Head and neck squamous cell carcinoma is the most common malignancy in Indian male.(1) Purpose of direct laryngoscopy using Jackson or Negus laryngoscope is to assess the exact extent of tumour in terms of involvement of vallecula,

'Financial or Other Competing Interest': None.

Submission 20-06-2019, Peer Review 15-07-2019,

Acceptance 17-07-2019, Published 29-07-2019.

Corresponding Author:

Dr. Devendra Kumar Gupta,

Head and Neck Oncosurgeon,

Army Hospital R \& R,

Dhaula Kua, Delhi Cantt, New Delhi-10, India

E-mail:docdk2000@yahoo.com

DOI: $10.14260 /$ jemds $/ 2019 / 521$

(c) $(7)$ oropharynx, tonsil, post cricoid, oesophagus, arytenoids, interarytenoid mucosa, subglottis and trachea. This assessment is of utmost importance for surgical planning of the patient amongst widely available surgical options from TOLS to open partial laryngectomies to total laryngectomy. This evaluation also is important to decide the type of reconstruction contemplated for that case as lifting the larynx off post pharyngeal wall will exactly reveal the mucosal extent and resection and its reconstruction in terms of primary closure, patch pharyngoplasty or a tubed reconstruction.

Subglottic extension and arytenoid involvement are very important in terms of partial laryngectomy. Extension in to trachea may require more extensive resection of trachea 
which may not be possible in certain cases transcervically.(2) (Figure 1, 2, 3)

Airway management is a very important aspect of head neck cancer evaluation as the upper airway is shared by the anaesthesiologist as well as the surgeon. The optimum outcome of the procedure entails a perfect understanding as well as discussion of limitations between the surgeon and the anaesthesiologist for each case in question. Moreover, otorhinolaryngologist or head and neck surgeon is the first point of contact for the patient, hence expected postoperative outcome need to be explained to the patient. We analysed over 300 patients who underwent general anaesthesia for head and neck diagnostic procedures.

The usual protocol for the diagnostic or short therapeutic direct laryngoscopy/ micro-laryngoscopy necessitate securing airway in terms of endotracheal or nasotracheal intubation.(3) However, this practice has its demerits also as the total duration of the procedure gets prolonged leading to an overall treatment time prolonged due to waiting list especially in a high volume centre for establishing a diagnosis as well as treatment planning. Endotracheal tube in situ also obscures the common field and hence compromises mapping especially, posterior part of laryngopharynx which need to be assessed in terms of laryngeal preservation procedures. The other technique is to carry out these procedures in short apnoea which involves brief period of apnoea supplemented with continuous oxygen insufflation, without endotracheal intubation. The advantage is that it takes less time and becomes a day care procedure, thus reducing costs. But it may not be considered absolutely safe as airway is not secured during the procedure and time available to the surgeon is also limited.(4,5,6) A very good understanding between the surgeon and anaesthesiologist is a must for this technique. We present our experience in 303 such patients and the methodology adopted for the same.

\section{METHODS}

IEC clearance was obtained to retrospectively evaluate consecutive HNSCC (Head neck squamous cell carcinoma) patients, who underwent diagnostic or therapeutic rigid laryngoscopy under anaesthesia between Dec 2015 till Jul 2017 (retrospective) and Aug 2017 till December 2018 (Prospectively maintained database) at a tertiary hospital

\section{Aims and Objectives}

1. To assess the merits and demerits of upper airway diagnostic procedures in HNSCC Head and Neck Squamous cell carcinoma under general anaesthesia with or without endotracheal intubation.

2. To derive factors which may lead to an airway emergency or endotracheal intubation.

\section{Participants}

Consecutive patients of HNSCC who underwent diagnostic endoscopy under anaesthesia for biopsy or mapping of the disease. 393 patients' data was screened out of which 303 patients were eligible for our study. 90 patients were excluded from the study, 30 were in stridor and 60 had a prior tracheotomy at the time of diagnostic evaluation.

\section{Exposure}

We retrospectively analysed the prospectively maintained database of patients of upper aero-digestive tract malignancy who underwent diagnostic or therapeutic direct laryngoscopy, micro-laryngoscopy or evaluation under anaesthesia with or without biopsy from Dec 2015 till Jul 2017 (Retrospective) and Aug 2017 till December 2018 (Prospectively maintained database) at a tertiary care head and neck cancer treatment center. Patients with prior tracheostomy and those in stridor were excluded from the study.

There were two sets of patients, first who underwent above diagnostic procedures with a standard endotracheal intubation and second group had patients without endotracheal intubation. These patients were subjected to Apnoea technique after induction with total intravenous anaesthesia. After supine positioning and attachment of all standard monitors (ECG, NIBP, EtCO 2 , Pulse Oximeter and Temperature), Patients were administered $100 \%$ oxygen (For pre-oxygenation) and intravenous propofol $1.5-2.5$ $\mathrm{mg} / \mathrm{kg}$ was administered as intravenous induction agent. After ascertaining adequate bag and mask ventilation, succinylcholine (Depolarising muscle relaxant) $2 \mathrm{mg} / \mathrm{kg}$ intravenous was administered and patient was handed over to surgeon for direct laryngoscopy/ microlaryngoscopy. During the procedure nasal prongs were used to deliver high flow oxygen @ 10-15 litres/minute as continuous insufflation. The procedure took approximately 3-5 minutes.

Various preoperative and intraoperative factors were analysed which might affect the difficulty of direct laryngoscopy or suspension laryngoscopy as well as requirement of intubation during diagnostic or therapeutic endoscopy of larynx, hypopharynx, oropharynx and oral cavity. The factors analysed were site of lesion (Oral tongue, tonsil, base of tongue, supraglottis, glottis, subglottis, marginal zone, pyriform sinus, post cricoid), per primum or post cancer directed treatment (Post radiotherapy, chemoradiotherapy, post-surgery or post-surgery + adjuvant treatment), various anaesthesia and laryngoscopy indices( Mallampati, Cormack Lehane, thyromental distance, 3:2:2 ratio), type of procedure (Direct laryngoscopy with or without biopsy, micro-laryngoscopy with or without therapeutic procedure, evaluation under anaesthesia). (Table 1)

\section{Statistical Analysis}

The factors evaluated were analysed using SPSS version 20 and cross tabulation were run to find correlation between factors and intubation.

\section{RESULTS}

Consecutive patients of HNSCC who underwent diagnostic endoscopy under anaesthesia for biopsy or mapping of the disease. 393 patients' data was screened out of which 303 patients were eligible for our study. 90 patients were excluded from the study, 30 were in stridor and 60 had a prior tracheotomy at the time of diagnostic evaluation. 


\begin{tabular}{|c|c|c|c|c|c|c|c|c|}
\hline \multirow{2}{*}{$\begin{array}{c}\text { Intubation Required } \\
\begin{array}{c}\text { Fibre Optic assessment } \\
\text { performed }\end{array}\end{array}$} & \multirow{2}{*}{\begin{tabular}{|l|} 
No $-254(83.8 \%)$ \\
No- $203(66.3 \%)$ \\
\end{tabular}} & \multirow{2}{*}{$\begin{array}{l}\text { Yes }-49(16.2 \%) \\
\text { Yes }-100(32 . \%)\end{array}$} & \multirow{2}{*}{\multicolumn{6}{|c|}{$\begin{array}{c}\text { FOB assisted intubation }-10 \\
(20.4 \% \text { of total intubation } n-49) \\
\text { all were post cancer directed treatment }\end{array}$}} \\
\hline & & & & & & & & \\
\hline Mallampati Class & $\mathrm{I}-109(36 \%)$ & II- $100(33 \%)$ & III- $48(15.8 \%)$ & IV- $46(15.2 \%)$ & & & & \\
\hline $\begin{array}{l}\text { Thyro- mental } \\
\text { distance }(\mathrm{cm})\end{array}$ & $>6.5-101(33.3 \%)$ & $\begin{array}{c}\text { 6- } 6.5-141 \\
(46.5 \%)\end{array}$ & $<6-61(20.1)$ & & & & & \\
\hline Cormack Lahane Score & $86(28.4 \%)$ & $2-101(33.3 \%)$ & 3- $58(19.1 \%)$ & 4- $58(19.1 \%)$ & & & & \\
\hline Tracheostomy & $\begin{array}{c}\text { Anticipated-56 } \\
(18.5 \%)\end{array}$ & $\begin{array}{c}\text { Not anticipated- } 247 \\
(81.6 \%)\end{array}$ & \begin{tabular}{|c|} 
Performed - $9(16 \%$ \\
of anticipated n-56)
\end{tabular} & $\begin{array}{l}\text { Not required\& not } \\
\text { anticipated }\end{array}$ & & & & \\
\hline Cord fixity & Yes- 77 (25.4\%) & $\begin{array}{l}\text { No- } 226 \\
(74.6 \%) \\
\end{array}$ & & & & & & \\
\hline Prior Treatment & $\begin{array}{c}\text { Treatment naïve } \\
225(74.3 \%)\end{array}$ & Post RT 36(11.9\%) & \begin{tabular}{|c|} 
Post Concurrent \\
Chemo RT $12(4.0 \%)$
\end{tabular} & \begin{tabular}{|c|} 
Post Major head neck \\
Surgery $18(5.9 \%)$ \\
\end{tabular} & $\begin{array}{l}\text { Post-Surgery + } \\
\text { CCRT } 12(4 \%)\end{array}$ & & & \\
\hline Site/ Procedure & $\begin{array}{c}\text { Oral Tongue/EUA } \\
26(8.6 \%)\end{array}$ & $\begin{array}{c}\text { Base of Tongue/ EUA + } \\
\text { DLS } \\
59(19.5 \%) \\
\end{array}$ & $\begin{array}{c}\text { Pyriform Sinus/ DLS } \\
93(30.7 \%)\end{array}$ & $\begin{array}{c}\text { Supraglottis/ DLS } \\
50(16.5 \%)\end{array}$ & $\begin{array}{c}\text { Post Cricoid/DLS } \\
17(5.6 \%)\end{array}$ & \begin{tabular}{|c|} 
Post Pharyngeal \\
wall/ DLS \\
$8(2.6 \%)$ \\
\end{tabular} & \begin{tabular}{|c|} 
Glottis/MLS \\
$34(11.2 \%)$
\end{tabular} & $\begin{array}{c}\text { Tonsil/EUA + } \\
\text { DLS } \\
16(5.3 \%) \\
\end{array}$ \\
\hline Procedure & \begin{tabular}{|c|} 
Direct Laryngoscopy \\
and biopsy \\
$187(61.8 \%)$ \\
\end{tabular} & $\begin{array}{c}\text { Direct Laryngoscopy } \\
30(9.9 \%) \\
\end{array}$ & $\begin{array}{l}\text { Microlaryngoscopy } \\
\text { and Biopsy } \\
28(9.2 \%) \\
\end{array}$ & \begin{tabular}{|c|} 
Microlaryngoscopy \\
and LASER excision \\
$15(4.9 \%)$ \\
\end{tabular} & $\begin{array}{r}\text { Evalua } \\
\text { wit }\end{array}$ & $\begin{array}{l}\text { lation under anaes } \\
\text { ith or without biop }\end{array}$ & $\begin{array}{l}\text { sthesia + DL Sc } \\
\text { psy } 43(14.2 \%\end{array}$ & \\
\hline
\end{tabular}

\begin{tabular}{|c|c|c|c|c|}
\hline Factors & $\begin{array}{c}\text { Intubation Required } \\
\text { No.(Percent) }\end{array}$ & \begin{tabular}{|c|}
$\begin{array}{c}\text { Intubation Not Required } \\
\text { No. (Percent) }\end{array}$ \\
\end{tabular} & \begin{tabular}{|c|}
$\begin{array}{c}\text { Percent of intubation } \\
\text { required }\end{array}$ \\
\end{tabular} & $\begin{array}{l}\text { P Value } \\
(95 \% \mathrm{CI})\end{array}$ \\
\hline \multicolumn{5}{|c|}{ Site } \\
\hline Oral Tongue (n-25) & 1 & 24 & 4 & $\mathrm{P}=0.13(0.2 \%$ to $1.8 \%)$ \\
\hline $\begin{array}{l}\text { Base Of Tongue } \\
(\mathrm{n}-63)\end{array}$ & 6 & 57 & 9.5 & $\mathrm{P}=0.17(0.3 \%$ to $1.7 \%)$ \\
\hline Tonsil (n-16) & $\mathbf{0}$ & 16 & 0 & $\mathrm{P}=0.19(0.6 \%$ to $1.5 \%)$ \\
\hline Pyriform Sinus (n-94) & 7 & 87 & 7.4 & $\mathrm{P}=0.20(0.7 \%$ to $2.8 \%)$ \\
\hline Post Cricoid (n-17) & $\mathbf{0}$ & 17 & 0 & $P=0.33(0.5 \%$ to $3.8 \%)$ \\
\hline Post Pharyngeal wall (n-9) & $\mathbf{0}$ & 9 & 0 & $\mathrm{P}=0.16(0.8 \%$ to $1.8 \%)$ \\
\hline Glottis(n-32) & 28 & 4 & 87.5 & $\mathrm{P}=0.03(0.03 \%$ to $1.8 \%)$ \\
\hline \multicolumn{5}{|c|}{ Prior Treatment } \\
\hline Treatment Naive(n-211) & 28 & 183 & 13.3 & $\mathrm{P}=0.66(0.7 \%$ to $2.8 \%)$ \\
\hline Post Radiotherapy (n-42) & 9 & 33 & 21.4 & $\mathrm{P}=0.05(0.3 \%$ to $1.9 \%)$ \\
\hline Post Concurrent Chemo-RT (n-15) & 5 & 10 & 33.3 & $\mathrm{P}=0.05(0.3 \%$ to $1.9 \%)$ \\
\hline Post Major Head Neck Surgery (n-20) & 2 & 18 & 10 & $\mathrm{P}=0.05(0.3 \%$ to $1.9 \%)$ \\
\hline Post-Surgery + Adjuvant RT / CCRT (n-15) & 5 & 10 & 33.3 & $\mathrm{P}=0.05(0.3 \%$ to $1.9 \%)$ \\
\hline \multicolumn{5}{|c|}{ Procedure } \\
\hline Direct Laryngoscopy with biopsy(n-187) & 9 & 178 & 4.8 & $\mathrm{P}=0.45(0.7 \%$ to $2.9 \%)$ \\
\hline Microlaryngoscopy and TOLS (n-15) & 15 & $\mathbf{0}$ & 100 & $\mathrm{P}=0.001(0.01 \%$ to $0.9 \%)$ \\
\hline $\begin{array}{l}\text { Evaluation under anaesthesia without direct } \\
\text { laryngoscopy }(\mathrm{n}-43)\end{array}$ & 2 & 41 & 4.7 & $P=0.41(0.6 \%$ to $1.9 \%)$ \\
\hline \multicolumn{5}{|c|}{ Laryngoscopy Indices } \\
\hline Mallampati I(n-106) & 16 & 90 & 15.1 & $\mathrm{P}=0.43(0.7 \%$ to $2.9 \%)$ \\
\hline Mallampati II (n-103) & $15(4.9)$ & $88(29)$ & 14.6 & $\mathrm{P}=0.40(0.8 \%$ to $2.6 \%)$ \\
\hline Mallampati III (n-49) & $8((2.6)$ & $41(13.5)$ & 16.3 & $\mathrm{P}=0.39(0.5 \%$ to $1.7 \%)$ \\
\hline Mallampati IV (n-45) & $10(3.3)$ & $35(11.5)$ & 22.2 & $\mathrm{P}=0.35(0.6 \%$ to $2.9 \%)$ \\
\hline $\begin{array}{l}\text { Thyromental Distance } \\
>6.5 \mathrm{cM}(\mathrm{n}-101)\end{array}$ & $20(6.6)$ & $81(26.7)$ & 19.8 & $P=0.28(0.2 \%$ to $1.5 \%)$ \\
\hline $\begin{array}{c}\text { Thyromental Distance } \\
6-6.5 \mathrm{~cm}(\mathrm{n}-141)\end{array}$ & $19(6.2)$ & $122(40.2)$ & 13.5 & $\mathrm{P}=0.17(0.9 \%$ to $1.9 \%)$ \\
\hline $\begin{array}{l}\text { Thyromental Distance } \\
<6 \mathrm{~cm}(\mathrm{n}-61)\end{array}$ & $10(3.3)$ & $51(16.8)$ & 16.4 & $\mathrm{P}=0.40(0.4 \%$ to $2.1 \%)$ \\
\hline Cormack Lehane I (n-87) & $11(3.6)$ & $76(25.0)$ & 12.6 & $\mathrm{P}=0.31(0.6 \%$ to $1.0 \%)$ \\
\hline Cormack Lehane II (n-101) & $16(5.2)$ & $85(28.0)$ & 15.8 & $\mathrm{P}=0.40(0.8 \%$ to $1.9 \%)$ \\
\hline Cormack Lehane III (n-58) & $10(3.3)$ & $48(15.8)$ & 17.2 & $\mathrm{P}=0.43(0.5 \%$ to $3.9 \%)$ \\
\hline Cormack Lehane IV (n-57) & $12(3.9)$ & $45(14.8)$ & 21.1 & $\mathrm{P}=0.23(0.6 \%$ to $1.8 \%)$ \\
\hline \multicolumn{5}{|c|}{ Table 2. Intubation Requirement Versus Various Factors } \\
\hline
\end{tabular}

\begin{tabular}{|c|c|c|c|}
\hline Prior Treatment & $\begin{array}{c}\text { Intubation } \\
\text { Required }\end{array}$ & $\begin{array}{c}\text { Intubation Not } \\
\text { Required }\end{array}$ & \multirow{2}{*}{ Odds Ratio 1.93} \\
\hline Yes & $\mathbf{2 1}$ & $\mathbf{7 1}$ & \\
\hline No & $\mathbf{2 8}$ & $\mathbf{1 8 3}$ & \\
\hline \multicolumn{2}{|c|}{ Table 3. Odds Ratio of Prior Treatment for Intubation } \\
\hline
\end{tabular}

\begin{tabular}{|c|c|c|c|c|}
\hline & $\begin{array}{c}\text { Intubation } \\
\text { Required }\end{array}$ & $\begin{array}{c}\text { Intubation Not } \\
\text { Required }\end{array}$ & Total & \multirow{3}{*}{ OR- 97.7} \\
\hline \begin{tabular}{|c|} 
ML Scopy with or \\
without LASER
\end{tabular} & 36 & 7 & 43 & \\
\hline $\begin{array}{c}\text { Non-MLS } \\
\text { procedure }\end{array}$ & 13 & 247 & 260 & \\
\hline
\end{tabular}

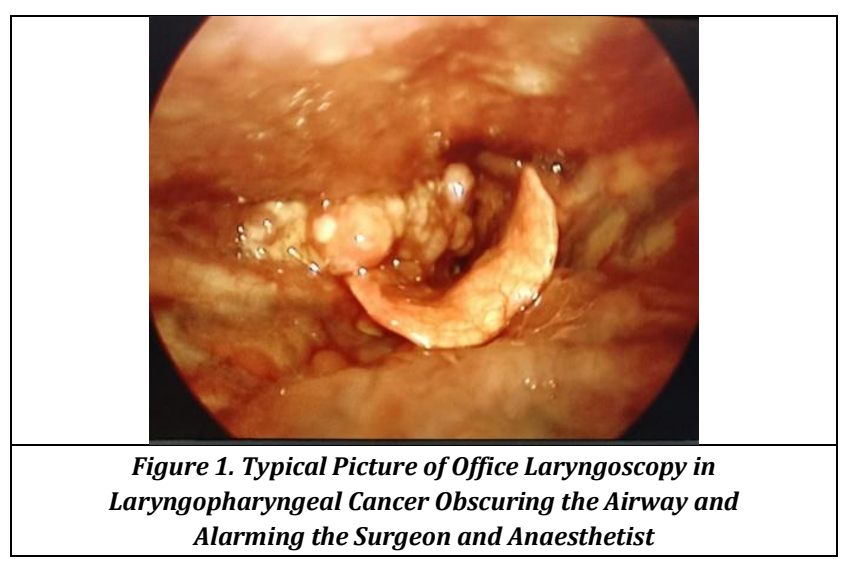



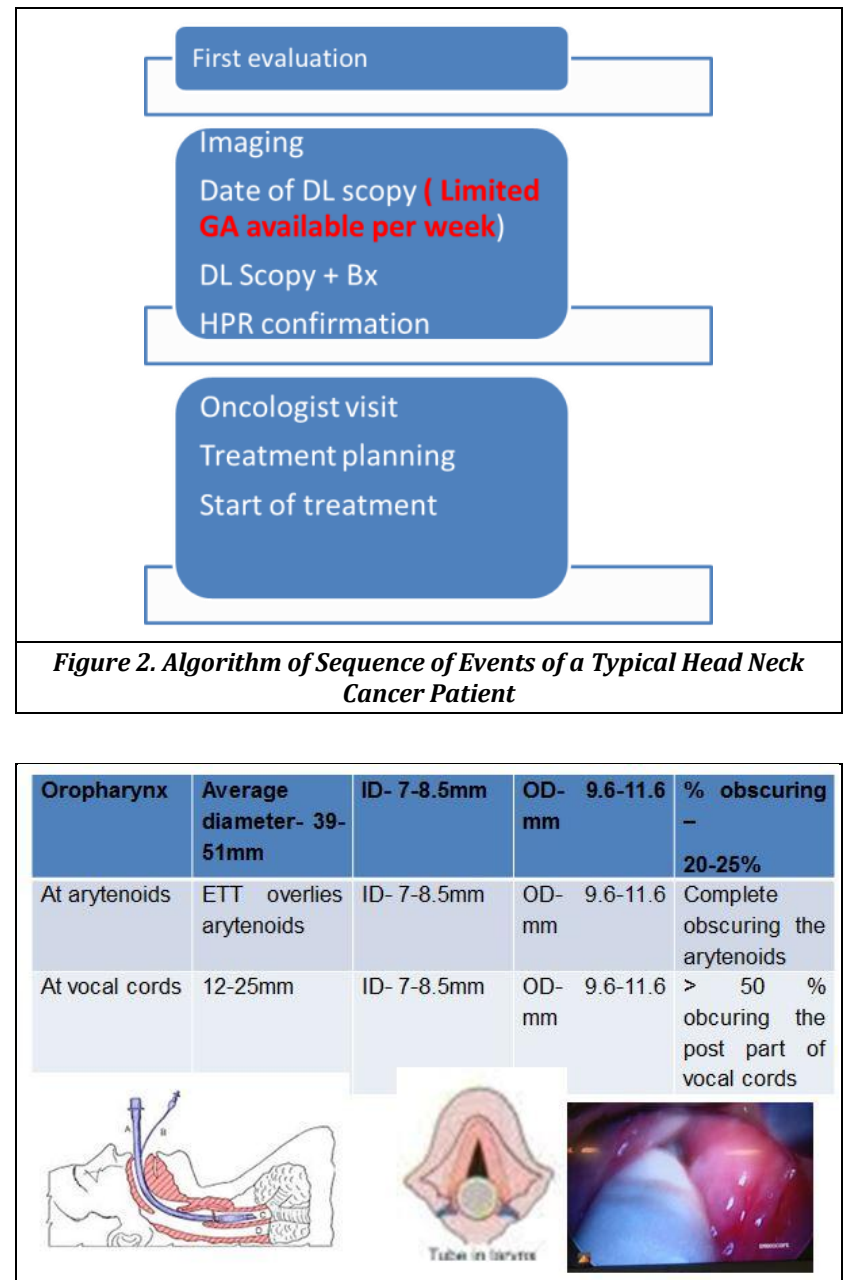

Figure 3. Relative Diameter of Endotracheal Tube Obscuring Upper Aerodigestive Tract for Diagnostic Direct Laryngoscopy

213 were male and 90 were female. Body mass index ranged from $18-36 \mathrm{Kg} / \mathrm{m} 2$ with a median of 22.5. $254(83.8$ $\%)$ did not require endotracheal intubation, however, 49 $(16.2 \%)$ required intubation. Out of 49 required intubation 10 required a fibreoptic assisted awake intubation in view of difficult airway, all of these were post cancer directed treatment for head neck cancer. Fibreoptic assessment was performed in $203(66.3 \%)$ patients. Tracheostomy was anticipated in $56(18.5 \%)$ and only $9(3 \%)$ required tracheostomy. None of the patients whom tracheostomy was not anticipated required tracheostomy. Majority of the patients were treatment naive 225 (74.3\%), 36 (11.9\%) were post radiotherapy, rest were post-surgery with or without chemoradiotherapy or concurrent chemoradiotherapy alone. Most of the patients were having a lesion either in hypopharynx or in larynx (Pyriform sinus- 93 (30.7\%), supraglottis- 50 (16.5\%), Glottis- 34(11.2\%), Base of tongue$59(19.5 \%)$.

Majority of patients underwent direct laryngoscopy with or without biopsy - 227(71.7\%), 43 (14.2\%) underwent evaluation under anaesthesia for carcinoma tongue for posterior extent along with direct laryngoscopy. 43 ( $14.1 \%$ ) underwent microlaryngoscopy with or without LASER resection of lesion in glottis. They were uniformly distributed in various anaesthesia indices like Mallampati, Cormack Lahane and thyromental distances. (Table 2)

On univariate analysis using SPSS version 20, site of lesion (Glottis), prior cancer directed treatment and type of procedure (Microlaryngoscopy) correlated significantly with requirement of intubation. However, on multivariate analysis microlaryngoscopy and prior treatment were the only factors which significantly affected the decision of intubation amongst this subset of patients. (Table 2)

The Odds ratio (HR) of prior treatment and microlaryngoscopy for requirement of intubation were 1.93 and 97 respectively.

\section{DISCUSSION}

Various indices which have been described may serve as important tools to preoperatively predict the airway and accordingly prepare the operative room for difficult intubation or surgical airway. The same may also help in better counseling of the patients. These tools are simple to comprehend and measure. ${ }^{(7,8)}$ All head neck surgeons should be well versed with their use to predict difficulty of direct laryngoscopy, as well as predict the exposure at microlaryngoscopy. However, for the requirement of intubation these indices did not affect significantly.

Altered anatomy is the most common factor for difficult intubation $(9,10)$ and was significant factor in our study also. Prior cancer directed treatment for the recurrent head neck cancer patients required intubation because of altered anatomy and neck fibrosis which significantly affected the requirement of intubation in our study $(\mathrm{P}=0.0595 \%$ confidence interval $0.3 \%$ to $1.9 \%$ ). Since this was a retrospective review at a single centre hence there are chances of selection bias, however treatment naïve patients can be safely taken up for diagnostic laryngoscopy without intubation.

\section{Site of Lesion}

Preoperative indirect laryngoscopy and imaging should be performed to know the site, size and extent of the lesion. It should be performed ideally by the surgeon who is going to perform diagnostic or therapeutic laryngoscopy. This indirect laryngoscopy provides the operating surgeon with the necessary information to plan for any special preparation, if required. However, other than glottis none of the other sites significantly affected the requirement of intubation-

1. Base of Tongue- Lesions on base of tongue will obscure the view of airway below and hence an apprehension to lose airway by the anaesthesiologist. If indirect laryngoscopy is done for intubation, there is a possibility of torrential bleed or the friable tumour may dislodge in the airway leading to airway emergency; hence a rigid direct laryngoscope (Kleinesaucer type) by the head neck surgeon/ ENT surgeon who has evaluated the lesion prior will have lesser chances of airway emergency.

2. Tonsil- Tonsillar lesions can be biopsied easily in an OPD setting under local anaesthesia. However, trans-oral resection with or without Robot/LASER has emerged as a major breakthrough in oropharyngeal malignancies and evaluation under anaesthesia to know the exact extent and depth is essential before undertaking the procedure. This is a short procedure and endotracheal intubation may not be necessary, as it might prolong the overall procedure time.

3. Supraglottis/Glottis- These lesions will obscure the view of vocal cords and lower airway making intubation 
difficult. Secondly, endotracheal tube will obscure the mapping of disease; hence evaluation by the surgeon without intubation is preferred. If intubation becomes necessary, the same can be done through direct laryngoscope after the mapping.

4. Marginal Zone/Pyriform Sinus- These are lateral lesions and usually do not obscure the airway. Very large or pedunculated lesions may cause ball valve type obstruction of the airway. In such situation, direct laryngoscopy with removal of the part of the tumour which is overlying the cords is attempted to secure the airway. Intubation again may lead to dislodgement of tumour in the lower airway causing airway emergency.

Apnoea technique with high flow oxygen through nasal prongs- After pre-oxygenation and induction with Propofol and Succinylcholine; direct laryngoscopy was performed with Kleinssaucers direct laryngoscope to map the mucosal extent of disease and to obtain biopsy. Average time taken for each procedure was 150 seconds with a range of 75 seconds to 300 seconds.

Microlaryngoscopy with or without LASER- suspension laryngoscopy done using direct laryngoscope and microscope at $400 \mathrm{~mm}$ focal length. Suspension laryngoscopy with microscope adjustment with or without LASER takes few minutes especially in a post graduate teaching institute, keeping residents training in consideration. Hence all Microlaryngoscopic procedures were undertaken using 5 to 5.5 size microlaryngoscopy tube. In a few cases where the lesion was extending up to post commissure or inter-arytenoid region, microlaryngoscopy was initiated without securing the airway; with intermittent endotracheal intubation through the suspension laryngoscope which was kept in situ.

Evaluation under Anaesthesia was performed like DL Scopy, and usually the two were combined to assess the lower extent of disease.

\section{CONCLUSIONS}

TIVA is safe and provides excellent view of the airway. Patient turn-over in high volume centres is very high \& hence cost effective. However, following points should be kept in mind-

1. Preoperative assessment of airway by the evaluating surgeon especially in post cancer directed treatment cases should be done.

2. Pre-procedure counseling of patient and attendants about chance of airway emergency and tracheostomy if deemed necessary, should be done.
3. Fibre optic flexible laryngoscopy along with difficult intubation cart needs to be kept standby in the operating room.

4. Microlaryngoscopy \& biopsies and definitive treatment requires longer duration and hence prior or intermittent endotracheal intubation is required.

\section{REFERENCES}

[1] https://www.uicc.org/news/new-global-cancer-dataglobocan-2018.

[2] Priest RE, Wesolowski S. Direct laryngoscopy under general anaesthesia. Trans Am Acad Ophthalmol Otolaryngol 1960;64:639-48.

[3] Woodman D. Laryngoscopy under general anaesthesia: apnoeic oxygenation technique. A report of over 100 cases. Ann Otol Rhinol Laryngol 1961;70:1113-6.

[4] Hogue CW Jr, Bowdle TA, O'Leary C, et al. A multicenter evaluation of total intravenous anaesthesia with remifentanil and propofol for elective inpatient surgery. Anaesth Analg 1996;83(2):279-85.

[5] Succo G, Bussi M, Presutti L, et al. Supratracheal laryngectomy: current indications and contraindications. Acta Otorhinolaryngol Ital 2015;35(3):146-56.

[6] Armstrong M, Mark LJ, Snyder DS, et al. Safety of direct laryngoscopy as an outpatient procedure. Laryngoscope 1997;107(8):1060-5.

[7] Orosco RK, Lin HW, Bhattacharyya N. Safety of adult ambulatory direct laryngoscopy: revisits and complications. JAMA Otolaryngol Head Neck Surg 2015;141(8):685-9.

[8] Paul RR, Varghese AM, Mathew J, et al. Difficult laryngeal exposure in microlaryngoscopy: can it be predicted preoperatively? Indian J Otolaryngol Head Neck Surg 2016;68(1):65-70.

[9] Umesh G, Ellango A, Jasvinder $\mathrm{K}$, et al. Immediate postoperative airway obstruction secondary to airway edema following tumor excision from the neck. J Anaesth 2009;23(4):609-12.

[10] Ebert TJ, Muzi M, Berens R, et al. Sympathetic responses to induction of anaesthesia in humans with propofol or etomidate. Anaesthesiology 1992;76(5):725-33. 